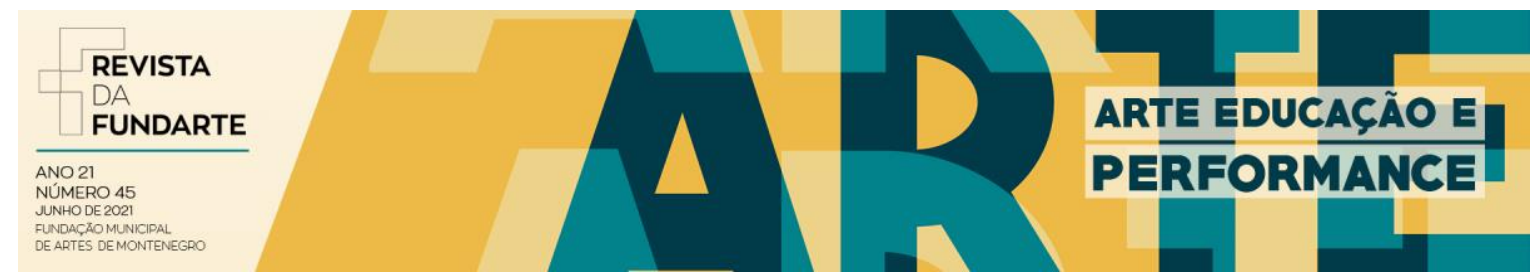

PARA A PRISÃO!

Daniel Aleixo

Pedro Ferreira

DOI: $10.19179 / 2319-0868 / 863$

ALEIXO, Daniel; FERREIRA, Pedro. Para a Prisão!. Revista da FUNDARTE. Montenegro, p.01-09, ano 21, no 45, junho de 2021.

Disponível em: http://.seer.fundarte.rs.gov.br/index.php/revistadafundarte/index> 30 de junho de 2021. 


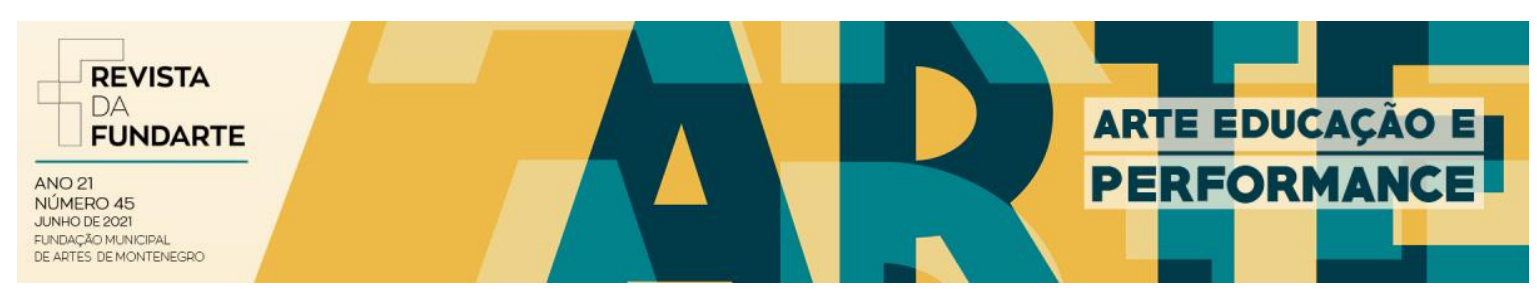

\title{
PARA A PRISÃO!
}

Daniel Aleixo ${ }^{1}$

Pedro Ferreira ${ }^{2}$

Resumo: o presente texto é uma tradução do manifesto publicado no Japão por Tatsumi Hljikata em 1961, originalmente intitulado Keimusho e (刑務所一). A versão da qual os tradutores se basearam é a publicada em inglês pela revista TDR/The Drama Review Spring 2000, Vol. 44, No. 1 (T165), pp. 43-48. O manifesto Para prisão! Foi escrito com teor surrealista expõe a abordagem de Hijikata às suas inquietações íntimas para com a marginalidade urbana e a perda da inocência na infância a fim de desenvolver uma dança criminal e que considere as trevas presentes dentro de cada corpo. Tratase de um marco ensaístico após início da sua investigação sobre a concepção da dança butô desde a criação em 1959. Dançar é um exercício continuo de desbravar o que existe de oculto na própria carne e fazê-la se expressar por si só; a dança por ela mesma, a necessidade e a violência de um soldado nu, a arma letal que sonha. Nesse momento, Hijikata inicia seu debruçar sobre o corpo de carne, ou nikutai (肉体).

Palavras-chave: Butô; Soldado nu; Tatsumi Hijikata; Dança das trevas; Dança criminal; Corpo de carne.

\section{TO PRISON!}

\begin{abstract}
Japan by Tatsumi Hljikata in 1961, originally titled Keimusho e (刑務所 $\sim$ ). The version on which the translators relied is that published in English by TDR / The Drama Review Spring 2000, Vol. 44, No. 1 (T165), pp. 43-48. The manifest To prison! was written with a surrealist content that exposes Hijikata's approach to his intimate concerns about urban marginality and the loss of innocence in childhood in order to develop a criminal dance that takes into account the darkness present within each body. This is an essay milestone after starting his research on the conception of butoh dance since its creation in 1959. Dancing is a continuous exercise of discovering what is hidden in the flesh and making it express itself; the dance for itself, the need and violence of a naked soldier, the lethal weapon that dreams. At that moment, Hijikata begins to focus on the body of flesh, or nikutai (肉体).
\end{abstract}

Keywords: Butoh; naked soldier; Tatsumi Hijikata; Dance of darkness; Criminal dance; Body of flesh.

Eu, que peguei um resfriado por olhar uma pedra e fiquei ansioso ao ver uma paisagem com ninguém nela, cresci pensando que era aleijado. Um dia um homem parou próximo a meu pai; uma árvore estalou e meu pai caiu. Agarrando uma pedra,

\footnotetext{
${ }^{1}$ Ator-pesquisador graduando em Artes Cênicas na Universidade Estadual de Campinas (UNICAMP) (2016 - 2022), tendo realizado intercâmbio na Universidade de Estudos Estrangeiros de Tóquio (2019-2020). Foca seus estudos científicos no teatro, no cinema e na dança do Japão assim como diálogos entre a arte e as contraculturas do século XX. Costuma elaborar pesquisas científicas de cunho prático-teórico.
}

2 Ator-pesquisador bacharel em Artes Cênicas na Universidade Estadual de Campinas (UNICAMP) (2016-2021), membro do grupo Casca de teatro e do grupo Criados Mudos. 


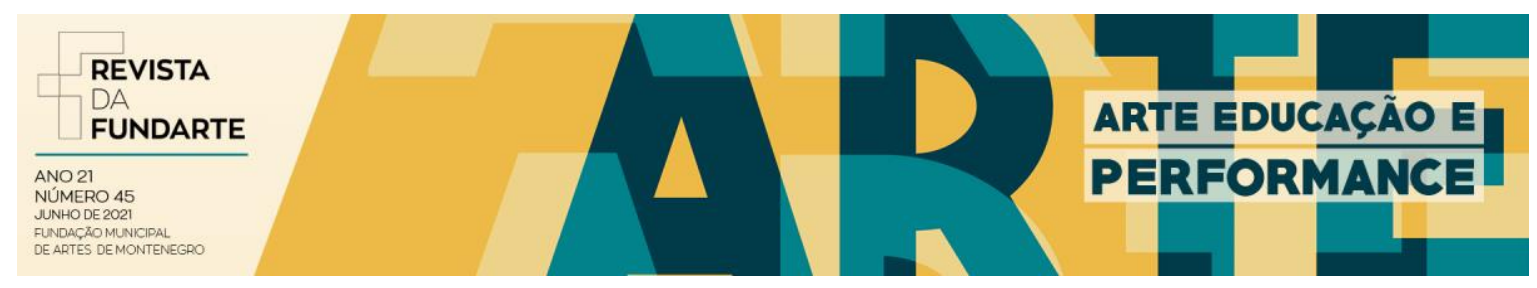

eu resisti; meu pai estava sendo espancado. Aquele foi o início da minha percepção de um mundo infeliz. Deve haver, entretanto, enganos mais produtivos na natureza hemorrágica.

Cresci habituado a farejar criminosos, isto é, tal companhia como a deles. Todos carregam o fardo de ser uma criança humana, ansiando por companheiros com os quais fugir de casa. Minha raiva sobre essa solidão era ampla.

Uma gangue de companheiros contém a diversidade de cheiros. A palavra "mundo" era nada além de delírio para mim, que havia passado a infância como um vira-lata. A natureza hemorrágica sempre transborda as atribuições da história e da sociologia, e meu olhar nunca se acorvadou dela. Os amigos que fiz em Tóquio eram, por assim dizer, habitantes do "mundo" transparente e mecânico, sem ligações com a natureza hemorrágica e mesmo sem cheiro. Não podia evitar vê-los como cadáveres.

Não há algum trabalho que espalhe putrefação absoluta e terror gráfico pelo mundo? Eu sempre pensei que gostaria de botar minhas mãos no eixo de fúria que sustenta tal espécie de trabalho.

Hoje não sou mais um cachorro. Embora desajeitadamente, muito desajeitadamente, estou definitivamente me recuperando. $\mathrm{O}$ que, porém, implica minha recuperação? O que recuperação significa para mim? Já não estou recuperado? Não continuo a recuperar para estar doente? Em qualquer caso, minha situação atual é a de andar por uma sala com as janelas bem abertas enquanto seguro um mosquete.

Estou desesperadamente tentando escapar do porão da liberdade de estar amarrado e da relação entre as cordas usadas para amarrar. Eu era frustrado na infância por conversas sobre um arrozal desafortunado. Uma certeza, porém, nunca mais serei enganado por esse cheque sem fundo chamado democracia. Nenhuma correspondência futura me alcançará por pombas levemente sujas libertas pelas mãos da sociedade e estou forçando silêncio também na minha juventude, quando não era nem um cachorro lambendo as feridas do capitalismo. De qualquer forma, tenho um mosquete apontado para a janela. Mas por algum motivo meu dedo não 


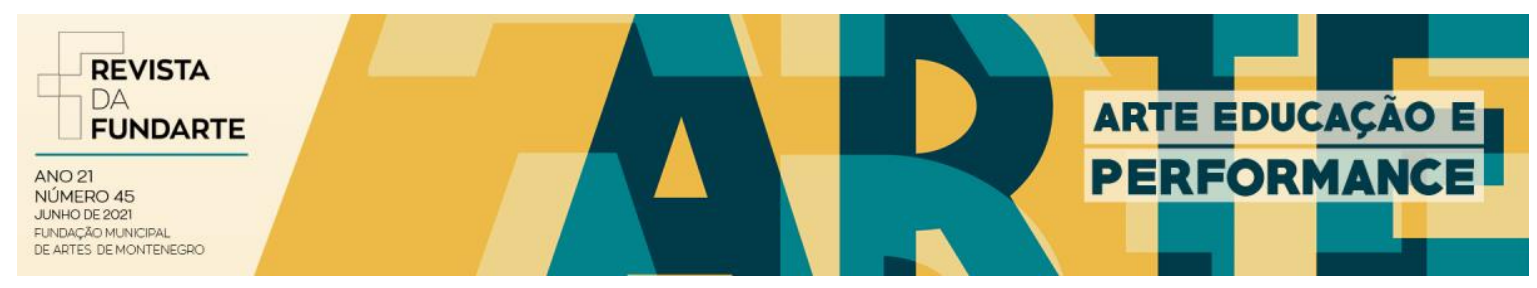

alcança o gatilho. Há miséria maior do que confiar um sonho a uma realidade da qual terá que se acordar um dia? Eu deveria fechar a janela imediatamente e continuar a conversação entre esta, minha única vida, e o universo. O que fui incapaz de encontrar até na infância... Eu, enfim, terminei de me transformar de um cão a uma criatura viva chamada um ser humano.

De repente um corpo nu veio à mira da arma. O corpo nu está sangrando. Em meio a uma fúria que remete a uma continuidade, faço consertos nos braços e nas pernas, que constantemente se perdem em um corpo orgânico individual. Esquecendo a origem das pernas e até a dos braços. Eu sou um mercado corporal; minha profissão é o trabalho da reabilitação humana, que hoje passa pelo nome de dançarino.

Todo o poder da moral civilizada, de mãos dadas com o sistema econômico capitalista e suas instituições políticas, é totalmente oposto ao uso do corpo simplesmente como meio, ferramenta ou propósito do prazer. Ainda mais, para uma sociedade orientada pela produtividade, o uso despropositado do corpo, que eu chamo de dança, é um inimigo mortal que deve ser tabu. Posso dizer que minha dança tem uma base em comum com crime, homosexualidade masculina, festivais e rituais porque é um comportamento que explicitamente ostenta sua falta de propósito perante uma sociedade orientada pela produtividade. Neste sentido minha dança, baseada na auto-ativação humana, incluindo homosexualidade masculina, crime e uma luta ingênua contra a natureza, pode naturalmente ser um protesto contra a "alienação do trabalho" na sociedade capitalista. Esta é também a provável razão para eu me envolver expressivamente com criminosos.

Há alguns pontos em comum no comportamento taciturno dos criminosos, e há erros devastadores que se estendem além. Sou sempre arrastado pelas pernas dos jovens criminosos hoje que passam por mim. São pernas que nunca carregaram política como cúmplices para bagunçar. Jovens que perseguem, além da suspeita, a medicina interna e a faca cirúrgica que a civilização de hoje entrega a eles. Eu aposto a realidade na vitalidade sem sentido que expurgou o eco da lógica de meu corpo e sonho com o dia em que serei enviado para a prisão com eles. Na prisão eu 


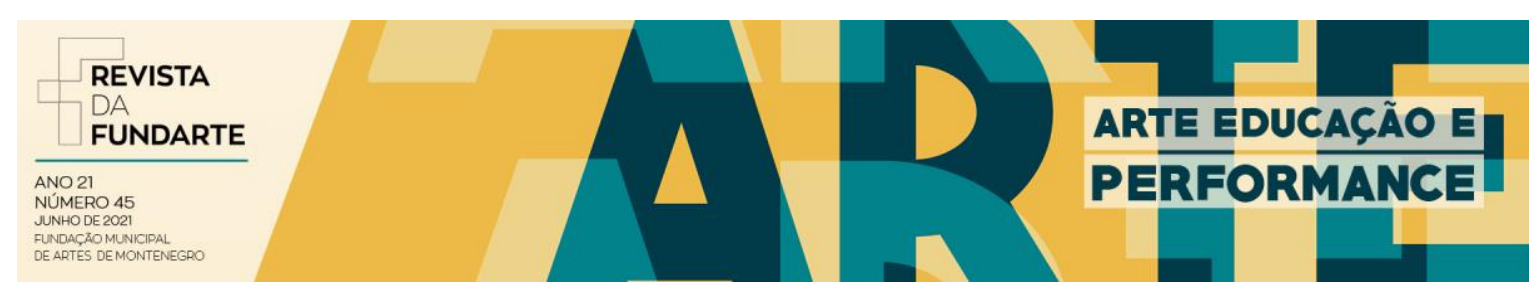

aprenderei a jogar futebol. São as pernas de criminosos com nenhuma necessidade de aprender a ficar em tal lugar. Eu estou estudando esse tipo de "dança criminal".

No mundo exterior, criminosos sempre foram forçados a permanecer de pé. $\mathrm{Na}$ realidade exterior, eles experienciam completamente que não há algo digno de crença. De vários pontos de vista, uma família para eles não pode ser uma única unidade onde sejam capazes de sentar. Material de hoje, eles adquiriram um instinto protetor de que pensar é perigoso. Primeiramente, eu proponho começar com uma composição em que eu fico de pé e eles também. Eu ando e eles também. Súbito, eles começam a correr e eu corro também. Eu caio. Eles correm. Eles se levantam sem feridas de onde caíram. Por que o lugar de onde eles se levantam é diferente daquele em que levantei sangrando? É fútil, no fim, questionar o que constantemente causa minhas atividades a erodirem. Remodelamento humano é atingido apenas na conexão com jovens que incessantemente experimentam os movimentos naturais que chutam a matriz do bom senso de hoje. Eu sonho com tal dança criminal. Não haverá mais hesitação sobre queimar teatros.

Para o espaço aberto. Na vida real eu sou capaz de me tornar um assassino de segunda categoria. Gostaria de ter minha própria subjetividade, que vacila em misturar e confundir o processo imaginativo e o processo da vida real. Gostaria de estar sentado, mesmo sem passaporte, um vestígio no meio de um erro.

De um quarto fechado ao espaço aberto, do espaço aberto à prisão - será inevitavelmente meu caminho. Meu corpo nu será carregado sem qualquer pretexto de inconveniência. Será permitido passar sem qualquer inspeção de meus efeitos pessoais, e eu terei outro olhar da dança que pode ser narrada por mãos nuas e pelo andar. A frase "andar incansavelmente" sempre aponta para a essência da dança. Georges Bataille disse, "A nudez oferece um contraste à auto-possessão, à existência discontínua, em outras palavras." Ele também disse, "É um estado de comunicação revelando uma busca pela possível continuidade de ser, além dos limites de si mesmo. Corpos se abrem a um estado de continuidade através de canais secretos que nos dão um sentimento de obscenidade. Ficar nu é visto em civilizações onde o ato tem total significância, se não como um simulacro do ato de 


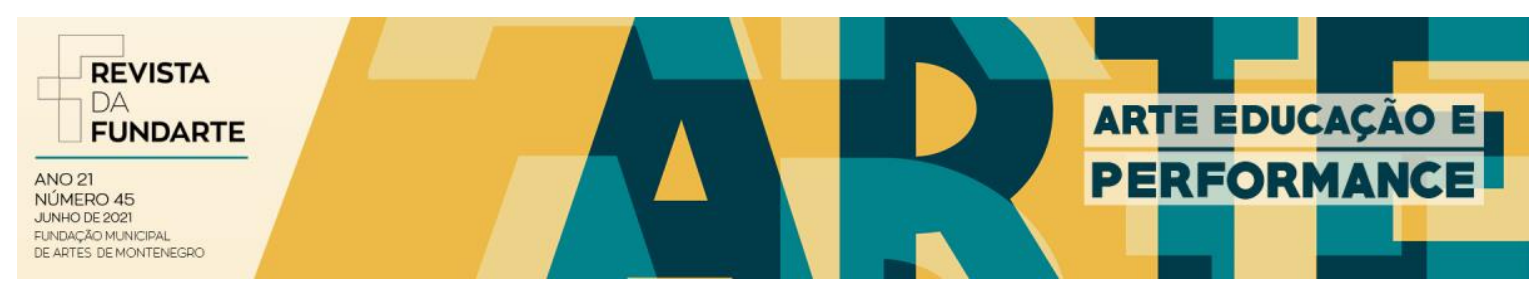

matar, ao menos como um equivalente tosado da gravidade." Estas palavras de Bataille parecem se aproximar mais precisamente da solidariedade humana de um corpo pelado, que é primeiro obtida, mesmo com o corpo solitário, através da continuidade de ser, ou seja, a morte. Eu vejo na prisão tal estado de tragédia, um estágio do drama em que o corpo nu e a morte estão inseparavelmente unidos.

Que eu fico pasmo com a beleza de um portão de prisão é nada além de uma postura de perplexidade dentro de mim, feita para permanecer à mínima distância de estar pelado. É assim o quão aterrorizante é estar nu, embora no mundo exterior já estamos completamente nus. Pois hoje a autoridade e significância de um portão de prisão se fechando está declinando. Em qualquer caso, é equivalente a ser libertado. Serei carregado alegremente. A fala proibida, o som maquinado para não alcançar meus ouvidos, em veste de cor indeterminada, eu continuarei consciente de que ainda estou pelado.

Nenhum teatro se compara a este, que está equipado com um perfeito mecanismo para meus atos destrutivos contra a produção e a moralidade. Vejo minha própria dança como um grupo jovial se banhando na prisão e vejo prisioneiros no corredor da morte na queda da civilização moderna e no brasão de família de seu bom senso. Vejo a forma original da minha dança em seu caminhar.

Um criminoso no corredor da morte ao andar para a guilhotina já é uma pessoa morta, mesmo se apegando, até o final, à vida. O feroz antagonismo entre vida e morte é levado ao extremo e coesamente expresso naquele ser solitário e miserável, que, em nome da lei, é forçado a uma condição injusta. Uma pessoa não caminhando, mas forçada a caminhar; uma pessoa que não vive, mas forçada a viver; uma pessoa não morta, mas forçada a morrer, deve, apesar da total passividade, paradoxalmente expôr a radical vitalidade da natureza humana. Sartre escreveu: "Um criminoso com as mãos amarradas agora de pé no cadafalso, ainda não está morto. Falta um momento para a morte, aquele momento de vida que intensamente deseja a morte." Esta mesma condição é a forma original de dança e é minha tarefa criar exatamente esta condição no palco. 


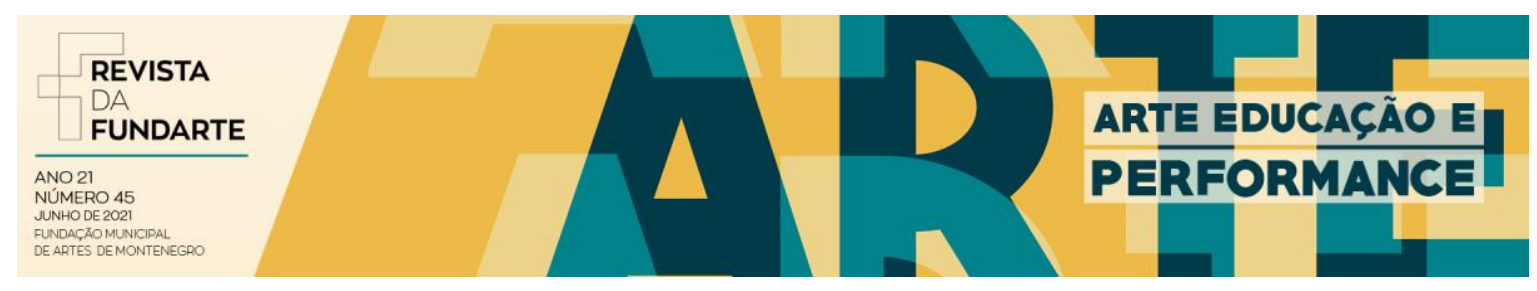

Mandar trabalhos histéricos para o teatro tem muito significado atualmente. Temos o direito de pedir por uma garantia de atualidade entre o barulho aleatório e o mau gosto que são equivalentes a materiais quase crus. $O$ ascetismo sublime do crime. Uma face totalmente vazia que suporta tortura. Jovens que adquiriram espertamente uma vitalidade sem sentido. O puro desespero que emerge antes da esperança ser massacrada. Minha tarefa é organizar estes em um grupo de dança e fazê-los soldados nus.

Desejando ascetismo, a geração de hoje vacila. Pode ser entendido que a maior parte (membros da Força de Autodefesa) abandonou a solidariedade com a carne de sua geração e se jogaram no Exército mais por vontade de estarem conectados do que para ter uma profissão. A dança, que é uma mistura entre o espírito e um impulso para um ritual secreto pelo bem de ser derramado na carne e sangue das pessoas jovens, acaba por finalizá-los como armas letais que sonham.

Aquilo que é capaz de confrontar a condição de hoje, que engloba as distorções de uma solidariedade partida em pedaços, não é nada mais do que o estabelecimento de uma nova imagem humana individual e a aquisição daquela solidariedade. Eu coloco essa solidariedade dentro do espectro do meu trabalho. Eu tento pressionar os limites de mim mesmo e de meu material. Pela natureza do meu trabalho, seres vivos são meu material. Eles são jovens seres vivos que controlam suas línguas. Jean Genet escreveu: "Talento é cortesia com respeito à matéria; consiste em dar música àquilo que era estúpido. Meu talento será o amor que sinto por aquilo que constitui o mundo das prisões e colônias penais". Estas palavras, completa e exatamente, levam à minha determinação. "Alguém tem, " nas palavras de Nietzsche, "de despir as roupas da percepção estéril desenhada pela civilização contemporânea" dessas pessoas jovens que calam suas bocas antes e depois de qualquer ação. Nietzsche também disse: "Meu trabalho é reanimar com vitalidade um esqueleto reunido a partir da consciência de ser uma vítima. Sou um homem de uma paixão simples e sensual. O senso de tragédia aumenta e diminui com sensualidade." Porque eu sou, como nas palavras de Nietzsche, um homem de paixão sensual, meu trabalho em todos os aspectos é o seguinte: Que tenho que 


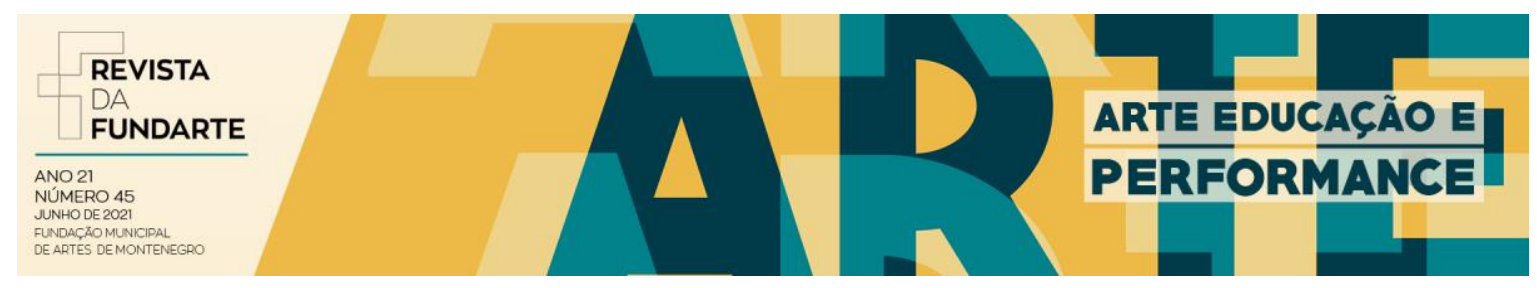

continuar ainda a aprender muito mais coisas sobre decepar cabeças com uma enxada. Que, por minha própria vontade, tenho que agarrar uma arma letal em minhas mãos. Preciso primeiro tentar recuperar estas mãos. Estas novas mãos, para que possam operar uma máquina, tem que ser amparadas pelas mãos que seguraram a enxada; não são mãos que lamentam um acidente de trabalho. Tenho que cortar estes dedos finos e longos que brincam com fragmentos. "Trabalho é a priori poder e provocação em luta com a natureza; é a superação da resistência," disse (Herbert) Marcuse. Esta "provocação" é em minhas próprias palavras, "dança”.

Mas uma língua que lambe as feridas dessa civilização mecânica e fugidia, já extrapola o alcance de nossa provocação. Políticas que contém em seu seio uma função despida de sentido não são mais do que lugares para humanos incompetentes que começaram a ter dúvidas sobre si próprios desde o princípio. Devemos continuar a abrir a situação atual com mãos que seguram o apagador que limpa os sinais de um futuro impotente, daquela cultura de choro enlutado que existe no esqueleto de consciência da vítima. Estou colocando no corpo do meu trabalho um altar similar ao ascetismo defronte a um corpo humano purgado de impurezas. Meu trabalho é remover armas de brinquedo das garras da juventude de hoje, que se desenvolveu em circunstâncias estéreis, e terminá-la como soldados nus, como uma cultura nua.

Hoje não sei nada em termos de formação da alienação e da continuidade da dureza que o trabalho impõe a um corpo, que equivale com plantar numa fazenda pobre no verão. Na energia crua combinada com ritmo autônomo amparando aquele trabalho, há algo que quase lhe faz cobrir os olhos. Fazendeiros jovens perdem os anos dentro daquela energia. Bebês nascidos lá, crescem brincando, ainda hoje, com merda. A situação atual é que uma família inteira encontra conforto numa doença anal sofrida por uma criança de 6 anos, em uma plantação de terra ruim. As mãos dos pais estão conectadas a mãos que provocam os deuses. Este fenômeno faz um projeto a partir de um humor negro risível e isto parece para mim ser uma dança misteriosa. 


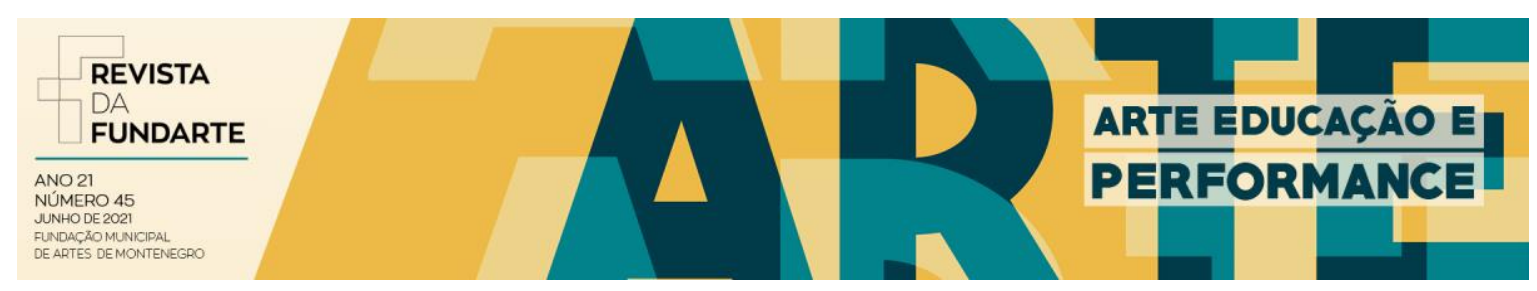

Por volta do $13^{\circ}$. Ano do período Showa (1938), as áreas de monocultura de Töhoku estavam desabilitadas por obstruções anais. Essas vozes chorosas devem ser gravadas outra vez na cultura da preservação. Apesar de estarem hoje se tornando um importante acompanhamento para minha dança, eram "choros tão primitivos" que apenas agora, 12 anos desde que passei a morar em Tókio, fui capaz de lidar com eles inteligentemente. Estou mastigando choros e a profundidade dos gestos esotéricos por vislumbrar atenta e incessantemente o mundano. Estou inventando uma caminhada moldada do presente, do alto da terra escura onde dançar e pular não podiam se unir. Quando menino, a terra escura do Japão foi minha professora em várias formas de desmaio. Tenho que trazer ao teatro aquele senso de trilhar. Sou um soldado voluntário nu que força este trilhar a confrontar o manuseio das pernas que foram domesticadas por pisos.

Coloco uma cerimônia de iniciação aos jovens como o altar do meu trabalho. É talvez semelhante ao ascetismo e pode ser chamada como cerimônia de amadurecimento. Eu gostaria de criar tal dança feita carne e sangue, que eu poderia começar com meu próprio corpo, não por mútuo entendimento, mas por sofrer o medo de acreditar e o ato de continuar a experienciar. Acreditar nas pessoas é hoje um trabalho solitário. Acreditar e continuar a viver são mitos de atos impossíveis de nomear. De arriscar. Com mãos que mediram o peso de testículos, eu substancio uma expressão cega.

Estou estupefato pelos corpos das jovens criaturas que, privadas de qualquer eco ético, tomam as ruas. Estou fazendo tema de meu trabalho as areias quentes, veículos velozes, perseguições dramáticas e conversações nuas que removeram a punição dada pela sociedade de sua realidade compartilhada de agir como uma juventude impossível de amar. Acredito - através de incessantes conversas com jovens criaturas que estão à mínima distância da experiência primordial e através de trabalhos que brincam com seus corpos - que eles podem ser aperfeiçoados como meus soldados nus. Remodelamento humanos será possível apenas se envolvendo com uma arma letal sonhante que há muito ignora a pobreza da política. 